\title{
Colchicine-induced polyploidization depends on tubulin polymerization in c-metaphase cells
}

\author{
A. D. Caperta ${ }^{1,2, *}$, M. Delgado ${ }^{1,2}$, F. Ressurreição ${ }^{1}$, A. Meister ${ }^{3}$, R. N. Jones ${ }^{4}$, W. Viegas ${ }^{1}$, and A. Houben ${ }^{5}$ \\ ${ }^{1}$ Secção de Genética, Centro de Botânica Aplicada à Agricultura, Instituto Superior de Agronomia, Universidade Técnica de Lisboa, Lisbon \\ ${ }^{2}$ Departamento de Ciências Naturais, Ambientais e Biotecnológicas, Universidade Lusófona de Humanidades e Tecnologias, Lisbon \\ ${ }^{3}$ Karyotype Evolution Group, Institut für Pflanzengenetik und Kulturpflanzenforschung, Gatersleben \\ ${ }^{4}$ Institute of Biological Sciences, University of Wales, Aberystwyth \\ ${ }^{5}$ Chromosome Structure and Function Group, Institut für Pflanzengenetik und Kulturpflanzenforschung, Gatersleben
}

Received March 10, 2005; accepted May 18, 2005; published online March 9, 2006

(C) Springer-Verlag 2006

\begin{abstract}
Summary. The microtubule cytoskeleton plays a crucial role in the cell cycle and in mitosis. Colchicine is a microtubule-depolymerizing agent that has long been used to induce chromosome individualization in cells arrested at metaphase and also in the induction of polyploid plants. Although attempts have been made to explain the processes and mechanisms underlying polyploidy induction, the role of the cytoskeleton still remains largely unknown. Through immunodetection of alpha-tubulin, different concentrations $(0.5$ or $5 \mathrm{mM})$ of colchicine were found to produce opposite effects in the organization of the cytoskeleton in rye (Secale cereale L.). A low concentration $(0.5 \mathrm{mM})$ induced depolymerization of the microtubular cytoskeleton in all phases of the cell cycle. In contrast, a high concentration $(5 \mathrm{mM})$ was found to induce the polymerization of new tubulin-containing structures in c-metaphase cells. Furthermore, both treatments also showed contrasting effects in the induction of polyploid cells. Flow cytometric analysis and quantitative assessments of nucleolus-organizing regions revealed that only the high-concentration colchicine treatment was effective in the formation of polyploid cells. Our studies indicate that spindle disruption alone is insufficient for the induction of polyploid cells. The absence of any tubulin structures in plants treated with colchicine at the low concentration induced cell anomalies, such as the occurrence of nuclei with irregular shape and/or (additional) micronuclei, $12 \mathrm{~h}$ after recovery, pointing to a direct effect on cell viability. In contrast, the almost insignificant level of cell anomalies in the high-concentration treatment suggests that the presence of new tubulin-containing structures allows the reconstitution of $4 \mathrm{C}$ nuclei and their progression into the cell cycle.
\end{abstract}

Keywords: Induced polyploidy; Colchicine; Tubulin array; Secale cereale.

\footnotetext{
* Correspondence and reprints: Secção de Genética, Centro de Botânica Aplicada à Agricultura, Instituto Superior de Agronomia, Universidade Técnica de Lisboa, Tapada da Ajuda, 1349-017, Lisboa, Portugal.

E-mail: anadelaunay@isa.utl.pt
}

\section{Introduction}

Cell division is a conserved process for cell proliferation in all eukaryotes. Nevertheless, there are several plantspecific aspects of cell division that are now starting to be unraveled (Dewitte and Murray 2003). One of these aspects relates to microtubule (MT) arrangements, a major component of the cytoskeleton and vital for cell function and viability. At the beginning of mitosis, the interphase arrays of cortical microtubules that are arranged transversely with respect to the main axis of growth rearrange into a narrow cortical ring, the preprophase band. This unique plant cell feature is replaced by the mitotic spindle, which segregates the chromosomes during anaphase. The microtubules then rearrange again to form the phragmoplast, another plant-specific cytoskeletal structure which organizes the synthesis of the new cell wall required between the daughter cells. Plant MT can be immunodetected through an epitope present in all isotypes of plant alpha-tubulin known so far (Breitling and Little 1986) and also with antibodies that specifically recognize tyrosinated alpha-tubulin, which represents a posttranslational modification of alpha-tubulin (Kilmartin et al. 1982, Gilmer et al. 1999).

Many inhibitors can be used to block cell cycle progression in cycling plant cells, such as the anti-mitotic drug colchicine used to induce blocking at metaphase of mitosis. Colchicine is an alkaloid extracted from Colchicum autumnale $\mathrm{L}$. which binds to tubulin dimers in vitro and 
results in the formation of a tubulin-colchicine complex acting primarily to prevent MT assembly (Panda et al. 1995). In vivo, colchicine interferes with the cytoskeleton by inducing MT depolymerization, preventing the formation of the mitotic spindle. This property is used to induce mitotic arrest in both animal and plant systems (Darlington and LaCour 1963, Planchais et al. 2000). While in animal cells colchicine is usually lethal even at the lowest concentrations necessary to block mitosis $\left(10^{-7} \mathrm{M}\right)$ (Eigsti and Dustin 1955, Rieder and Palazzo 1992), it presents an effective MT-depolymerizing agent in plants at millimolar or greater concentrations (Morejohn and Fosket 1991). The ability of plant cells to survive colchicine treatments has been used in the induction of polyploidy for more than 50 years (Eigsti and Dustin 1955, Hague and Jones 1987). Exposure to colchicine has a time-dependent effect on tubulin polymerization status. Short-time exposure to high concentrations results in the formation of new tubular arrays, detected by electron microscopy and immunofluorescence with tubulin-specific antibodies (Utrilla et al. 1989, Apostolakos et al. 1990, Karagiannidou et al. 1995). The disassembly of the mitotic spindle and the cellcycle-dependent formation of tubulin cortical strands other than MT in c-mitotic wheat cells exposed to high colchicine concentration has been reported recently (Lazareva et al. 2003).

It is generally accepted that inhibiting spindle assembly induces the formation of polyploid cells due to the lack of normal chromatid separation. Chromatids fail to move to the poles and eventually become enclosed in a new nuclear membrane and proceed into interphase as a doubled number of chromosomes (Hague and Jones 1987). Although this hypothesis is attractive, the nature of the process and mechanisms underlying polyploidy induction still are undefined.

In an attempt to answer this significant biological question on the mechanism of colchicine-induced polyploidization, we have used immunodetection of alpha-tubulin to analyze the effect of low and high colchicine concentrations upon the tubulin polymerization status immediately after a short-time exposure and during the first day of recovery for rye (Secale cereale L.). The degree of polyploidization was evaluated by flow cytometry, and quantitative assessment of nucleolus-organizing regions (NORs) was used to confirm the polyploid status.

Our studies indicate that spindle disruption alone is insufficient for the induction of polyploid cells. Here we show for the first time that the polymerization of new tubulin-containing structures is essential for the reconstitution of $4 \mathrm{C}$ nuclei and progression into the cell cycle.

\section{Material and methods}

\section{Plant material and growth conditions}

Seeds of an isogenic line of rye (Secale cereale L.) were germinated on moist filter paper in the dark for 2 days at $24{ }^{\circ} \mathrm{C}$. Seedlings were then completely immersed in a $0.5 \mathrm{mM}$ or $5 \mathrm{mM}$ aqueous colchicine solution (low or high concentration) for $2.5 \mathrm{~h}$ at $24^{\circ} \mathrm{C}$ in the dark. For recovery after treatment, seedlings were transferred onto water-moist filter paper for 3,12 , and $24 \mathrm{~h}$ and then grown in the dark at the same temperature. Control seedlings were immersed in water, with all other conditions and procedures maintained as described above.

\section{Cytological immunodetection of alpha-tubulin}

Root tips were excised and fixed in $4 \%(\mathrm{w} / \mathrm{v})$ formaldehyde in MTSB (50 mM piperazine- $\mathrm{N}, \mathrm{N}^{\prime}$-bis(2-ethanesulfonic acid), $5 \mathrm{mM} \mathrm{MgSO} \cdot 7 \mathrm{H}_{2} \mathrm{O}$, 5 mM EGTA, $\mathrm{pH}$ 6.9) for $45 \mathrm{~min}$ at room temperature, and then rinsed twice in MTSB. Cells were processed for subcellular localization of tubulin by indirect immunofluorescence (Wick and Duniec 1983). Briefly, fixed root tips, 1-2 mm in length, were excised, and cells were dispersed in multiwell slides coated with aminopropyltriethoxysilane (Sigma) and left to air dry. The cells were then permeabilized in $0.5 \%$ Triton X-100 in MTSB for $15 \mathrm{~min}$ and rinsed prior to labeling. MT were localized with the mouse monoclonal alpha-tubulin antibody DM1A (Serotec) diluted 1:100 in MTSB, which recognizes alpha-tubulin and not beta-tubulin. The tyrosinated form of the alpha-tubulin unit was detected with rat monoclonal alpha-tubulin antibody YL1/2 (Serotec) diluted 1:100 in MTSB. For indirect detection of DM1A, a secondary antibody conjugated with fluorescein isothiocyanate, diluted 1:300 in MTSB, was used, whereas for detection of YL1/2, a secondary antibody conjugated with biotin was diluted $1: 200$ in MTSB and further detected with a streptavidin-Cy3 conjugate (Sigma) diluted 1:700 in MTSB. For determination of the cell cycle phase, nuclei were counterstained with $1 \mu \mathrm{g}$ of DAPI (4',6-diamino-2-phenylindole dihydrochloride) per $\mathrm{ml}$ and mounted in antifade solution.

\section{Fluorescence in situ hybridization}

For the fluorescence in situ hybridization (FISH) procedure (Schwarzacher and Heslop-Harrison 2000), we used the DNA probe pTa71, a $9 \mathrm{~kb} E c o$ RI fragment of the ribosomal DNA from wheat (Triticum aestivum L.), containing the $5.8 \mathrm{~S}, 18 \mathrm{~S}, 25 \mathrm{~S}$, and nontranscribed spacer sequences (Gerlach and Bedbrook 1979), and labeled with dUDP fluorescein isothiocyanate conjugate. DNA was counterstained with DAPI.

\section{Cell analysis by epifluorescence microscopy and imaging}

Preparations were observed by epifluorescence microscopy (Leitz Biomed) with the appropriate filters. Images were collected using an AxionCam digital camera (Zeiss) controlled by AxioVision 3.0, and composited using Adobe Photoshop 5.0 (Adobe Systems Inc., Mountain View, Calif.).

\section{Flow cytometric analysis of nuclear suspensions}

Approximately $30 \mathrm{mg}$ of fresh root meristem material was chopped in a precooled petri dish with a razor blade in about $1 \mathrm{ml}$ of ice-cold Galbraith buffer $(45 \mathrm{mM} \mathrm{MgCl}, 30 \mathrm{mM} \mathrm{NaCl}, 20 \mathrm{mM}$ morpholinepropanesulfonic acid, $0.1 \%$ Triton X-100) (Galbraith et al. 1983). The resulting suspension was filtered through a nylon mesh (mesh size, $35 \mu \mathrm{m}$ ) and supplemented with $50 \mathrm{mg}$ of propidium iodide per $\mathrm{ml}$ for DNA staining and $50 \mathrm{mg}$ of DNase-free RNase (Boehringer Ingelheim) per $\mathrm{ml}$. The DNA content per nucleus was measured with a FACStar ${ }^{\text {PLUS }}$ flow cytometer (Becton Dickinson, San Jose, Calif.) 
equipped with an Innova 90-5 argon laser (Coherent, Santa Clara, Calif.) using the CellQuest analysis program.

Histograms representing the quantity of nuclei with distinct DNA contents were plotted using a logarithmic intensity scale (x-axis), giving all peaks of the histogram the same width (Givan 2001).

As a measure of ploidy level we used the Cycle value $(\mathrm{Cv})$, indicating the mean number of colchicine-induced polyploidization cycles per nucleus (Barow and Meister 2002). This is defined as

$\mathrm{Cv}=\left(0 n_{2 \mathrm{C}}+1 n_{4 \mathrm{C}}+2 n_{8 \mathrm{C}}+3 n_{16 \mathrm{C}} \cdots\right) /\left(n_{2 \mathrm{C}}+n_{4 \mathrm{C}}+n_{8 \mathrm{C}}+n_{16 \mathrm{C}} \cdots\right)$,

where $n_{2 \mathrm{C}}, n_{4 \mathrm{C}}, n_{8 \mathrm{C}}, \ldots$ are the numbers of nuclei with the corresponding C value $(2 \mathrm{C}, 4 \mathrm{C}, 8 \mathrm{C}, \ldots)$.

\section{Results}

Microtubule arrangements are disrupted after treatment with colchicine at low concentration

To characterize MT configurations during the cell cycle, cells were immunodetected with the DM1A antibody, which recognizes an epitope present in all isotypes of plant alpha-tubulin, and YL1/2, which recognizes tyrosinated alpha-tubulin.
A

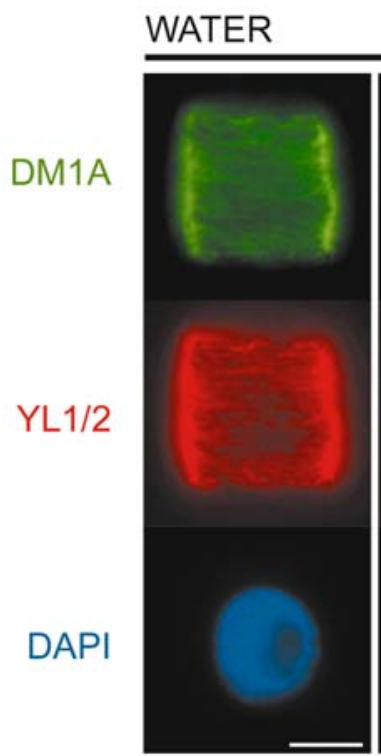

G1/S

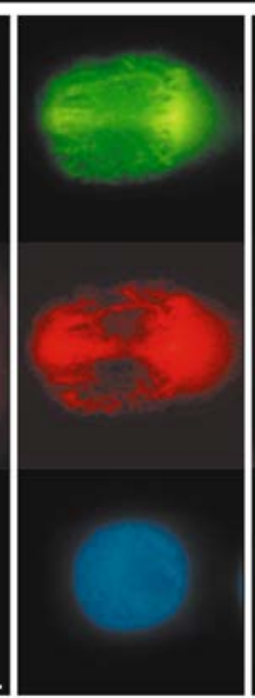

G2

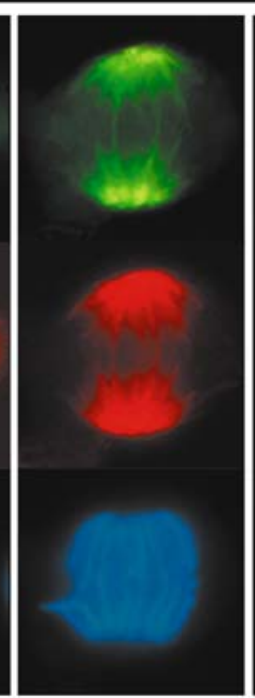

anaphase

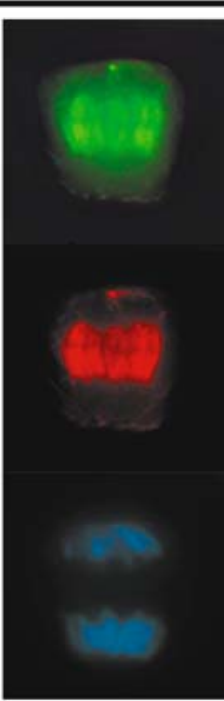

telophase

\section{B $0.5 \mathrm{mM}$ colchicine}

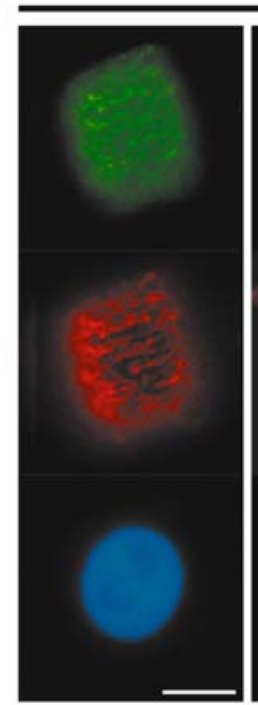

$\mathrm{G} 1 / \mathrm{S}$

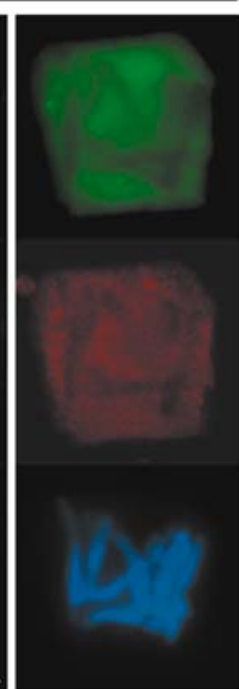

metaphase

\section{C $5 \mathrm{mM}$ colchicine}

DM1A

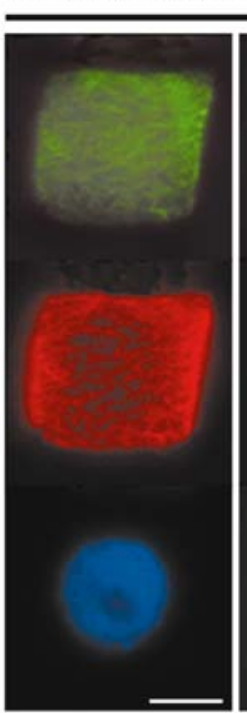

G1/S

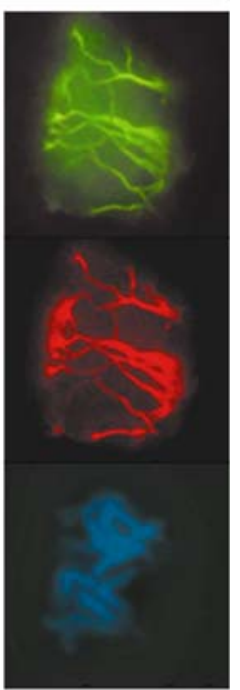

metaphase
Fig. 1 A-C. Indirect immunodetection of alpha-tubulin in Secale cereale meristematic root tip cells. Tubulin-containing arrays were simultaneously detected with the DM1A alpha-tubulin (green) and the YL1/2 tyrosinated alpha-tubulin (red) antibody. Nuclei and chromosomes were stained with DAPI (blue). A Untreated cells; from left to right: interphase cell with the cortical microtubules linked to plasmalemma; prophase cell with the preprophase band; anaphase cell with the mitotic apparatus; early telophase cell with the phragmoplast. B and C Cells immediately after exposure to colchicine treatments at different concentrations, 0.5 or $5 \mathrm{mM}$. B Low concentration $(0.5 \mathrm{mM})$ induced microtubule depolymerization: interphase cell $\left(\mathrm{G}_{1} / \mathrm{S}\right)$ showing diffuse labeling and c-metaphase cell with no detectable MT. C High concentration $(5 \mathrm{mM})$ disrupted the mitotic apparatus and induced the formation of new, highly tyrosinated, branched, stringy cortical strands at metaphase: interphase cell $\left(G_{1} / S\right)$ with a weak labeling of a "tubulin cage" wavy network and c-metaphase cell showing highly tyrosinated cortical strands. Bars: $10 \mu \mathrm{m}$ 
In control cells, the four characteristic cell-cycle-stagedependent MT arrangements were observed: cortical MT linked to plasmalemma, preprophase band, mitotic apparatus, and the phragmoplast (Fig. 1A).

After $2.5 \mathrm{~h}$ of exposure to $0.5 \mathrm{mM}$ colchicine, most cells presented discontinuous MT arrays (Fig. 1B, G $1 / \mathrm{S}$ cell) compared with those from untreated seedlings, except for c-metaphase cells, in which no MT were detectable (Fig. 1B, metaphase cell). $3 \mathrm{~h}$ after recovery from colchicine treatment, detectable but very weakly labeled cortical MT were revealed in interphase cells. The configurations preprophase band, mitotic apparatus, and phragmoplast were totally absent, while DAPI staining revealed all cell cycle stages.

Although reestablishment of the microtubular cytoskeleton occurred $12 \mathrm{~h}$ after recovery, $20.5 \%$ of the cells presented nuclei with an irregular shape and/or (additional) micronuclei in interphase.

\section{High concentration of colchicine induces new and highly tyrosinated tubulin-containing arrays}

Interphase and prophase cells treated with $5 \mathrm{mM}$ colchicine exhibited different tubulin-containing arrays and a "tubulin cage" wavy network that seemed to emanate from the plasmalemma immediately after treatment (Fig. 1C, $\mathrm{G}_{1} / \mathrm{S}$ cell). In these cells, a decrease in labeling intensity was observed, especially with the YL1/2 antibody. No telophase cells were detectable immediately after exposure to colchicine or $3 \mathrm{~h}$ after recovery from the treatment.

The most prominent feature was observed in c-metaphase cells, both at the end of the treatment (Fig. 1C, metaphase cell) and $3 \mathrm{~h}$ after recovery. The cells exhibited highly tyrosinated, branched, stringy cortical strands. $3 \mathrm{~h}$ after the recovery period, these new tubulin-containing arrays were still observed, but a tendency for a more parallel organization and an increase in the density of the arrays was also detected.

In the $0.5 \mathrm{mM}$ treatment, a complete reestablishment of the usual MT array configuration was reached after $12 \mathrm{~h}$ of recovery. However, in contrast to the low-concentration treatment, only $3 \%$ of cells in interphase exhibited nuclei with an irregular shape and/or (additional) micronuclei.

\section{Concentration-dependent effects of colchicine on ploidy level}

Contrasting effects of the two treatments on tubulin polymerization were correlated with the capacity to induce polyploid nuclei, as evaluated by flow cytometry. Following immersion in colchicine, the ploidy level was determined immediately and $24 \mathrm{~h}$ after the end of the treatment. In all cases, the $4 \mathrm{C}$ peak increased relative to the $2 \mathrm{C}$ peak after $24 \mathrm{~h}$, and the $\mathrm{S}$ phase (nuclei with an intermediate DNA content situated between both peaks) decreased during this time (Fig. 2). No effect of colchicine-induced polyploidy occurred after low-concentration treatment, either at the end of treatment or $24 \mathrm{~h}$ after the recovery period. The occurrence of polyploid nuclei was expressed in the appearance of an $8 \mathrm{C}$ peak in high-concentration-treated cells, but this developed only after $24 \mathrm{~h}$ recovery. The $\mathrm{Cv}$ as a parameter characterizing the degree of polyploidization increased with the colchicine concentration.

These changes in ploidy level are further supported by fluorescence in situ hybridization analysis of $45 \mathrm{~S}$ rDNA loci. Root tip cells exhibited two rDNA clusters localized

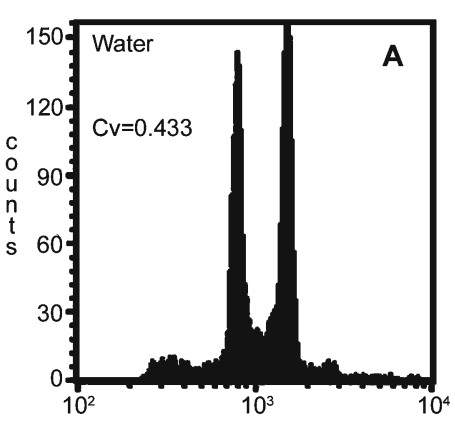

$\log$ DNA content

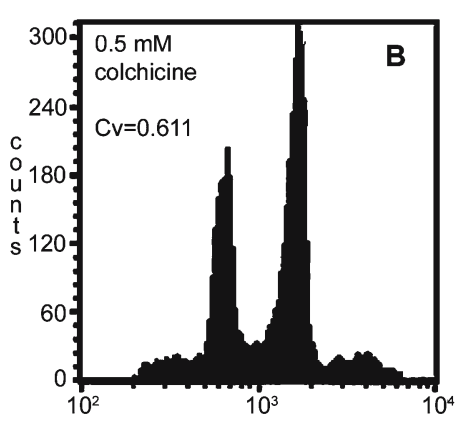

$\log$ DNA content

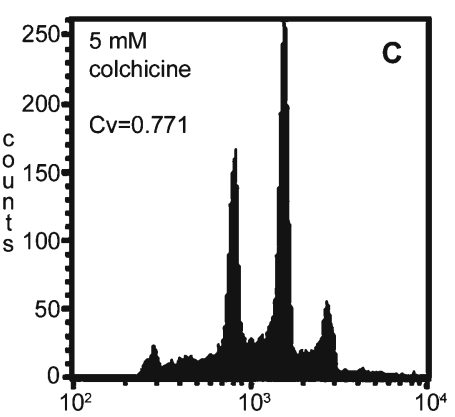

$\log$ DNA content

Fig. 2 A-C. Histogram of relative DNA content was obtained by flow-cytometric analysis of propidium iodide-stained nuclei released from Secale cereale root tips after $24 \mathrm{~h}$ of recovery from treatments. A Control water-grown seedlings; B low-concentration $(0.5 \mathrm{mM})$ colchicine-treated seedlings; $\mathbf{C}$ high-concentration $(5 \mathrm{mM})$ colchicine-treated seedlings. After low-concentration treatment, two clear $2 \mathrm{C}$ and $4 \mathrm{C}$ subpopulations of nuclei were detected, which contrasted with an additional, clearly visible polyploid $8 \mathrm{C}$ peak in high-concentration-treated root tips. A clear increase in the $\mathrm{Cv}$ was also observed with increments in colchicine concentration 
Table 1. Frequencies of Secale cereale nuclei with distinct numbers of NORs from meristematic root tips immediately and $24 \mathrm{~h}$ after colchicine treatment

\begin{tabular}{|c|c|c|c|c|c|c|}
\hline \multirow{3}{*}{$\begin{array}{l}\text { FISH } \\
\text { signals }^{a}\end{array}$} & \multicolumn{6}{|c|}{$\%$ Nuclei with NORs after treatment with: ${ }^{b}$} \\
\hline & \multicolumn{2}{|c|}{ Water } & \multicolumn{2}{|c|}{$\begin{array}{l}0.5 \mathrm{mM} \\
\text { colchicine }\end{array}$} & \multicolumn{2}{|c|}{$\begin{array}{l}5 \mathrm{mM} \\
\text { colchicine }\end{array}$} \\
\hline & $0 \mathrm{~h}$ & $24 \mathrm{~h}$ & $0 \mathrm{~h}$ & $24 \mathrm{~h}$ & $0 \mathrm{~h}$ & $24 \mathrm{~h}$ \\
\hline 2 & 99 & 99 & 99 & 98 & 93 & 75 \\
\hline 4 & 1 & 1 & 1 & 2 & 7 & 25 \\
\hline $\begin{array}{l}\text { Nr. of scored } \\
\text { nuclei }\end{array}$ & 138 & 188 & 152 & 149 & 154 & 169 \\
\hline
\end{tabular}

${ }^{a}$ FISH analysis was performed with the probe pTa71 specific for the ribosomal DNA from wheat (Triticum aestivum L.), containing the 5.8S, $18 \mathrm{~S}, 25 \mathrm{~S}$ and nontranscribed spacer sequences

${ }^{\mathrm{b}}$ No significant differences between treatments were detected at $0 \mathrm{~h}$ $\left(\chi^{2}=2.93, \mathrm{p}=0.23\right)$. After $24 \mathrm{~h}$ of recovery, no significant differences $\left(\chi^{2}=0.79, \mathrm{p}=0.37\right)$ were observed between the $0.5 \mathrm{mM}$ colchicine treatment and the water control; however, the $5 \mathrm{mM}$ colchicine treatment differed significantly $\left(\chi^{2}=73.04, \mathrm{p}=0.000\right)$

on the short arms of the $1 \mathrm{R}$ chromosomes which were detected with the pTa71 probe (Caperta et al. 2002). Interphase organization of rye $45 \mathrm{~S}$ rDNA characteristically shows two condensed perinucleolar knobs (Delgado et al. 1995, Caperta et al. 2002). In seedlings treated with the low colchicine concentration, only nuclei displaying two pTa71 signals, representing the perinucleolar knobs, were revealed. In contrast, four perinucleolar knobs appeared in $7 \%$ of the nuclei immediately after exposure to the high concentration, and this frequency increased up to $25 \% 24 \mathrm{~h}$ after recovery (Table 1 ). The cytological quantification of NORs (Fig. 3) $24 \mathrm{~h}$ after recovery through in situ hybridization confirmed the polyploid nature of $8 \mathrm{C}$ nuclei.
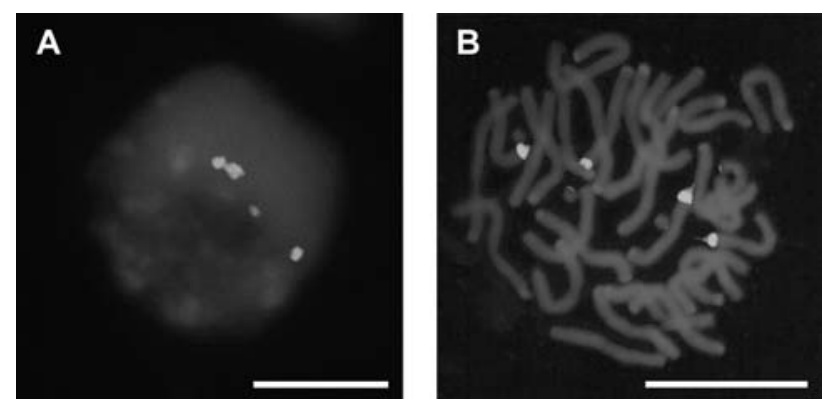

Fig. 3. Fluorescence in situ hybridization with a $45 \mathrm{~S}$ rRNA gene probe in Secale cereale meristematic root tip cells $24 \mathrm{~h}$ after exposure to $5 \mathrm{mM}$ colchicine treatment revealing four rDNA loci at interphase (A) and metaphase (B). DNA is DAPI stained. Bars: $10 \mu \mathrm{m}$

\section{Discussion}

We evaluated the effects of short-time exposure to high $(5 \mathrm{mM})$ and low $(0.5 \mathrm{mM})$ concentrations of colchicine upon the disruption of the cytoskeleton MT in rye root tip meristematic cells. After a $2.5 \mathrm{~h}$ exposure to a low concentration, we observed disassembly of the preprophase band, spindle, and phragmoplast. Conversely, cells exposed for a short period to a 10 -fold higher concentration revealed a dramatically different effect: the c-mitotic cells showed tubulin-containing stringy and branched cortical strands, as have been described in wheat (Lazareva et al. 2003). The differential effect of this treatment was also evident in interphase and prophase cells, in which an irregular "tubulin cage" wavy network replaced the typical MT arrays. It is possible that these newly polymerized tubulin-containing structures result from the modified interphase wavy network, a hypothesis that is consistent with the observation that MT can directly transform into helical filaments that rearrange into cortical strands in Allogromia laticollaris (Welnhofer and Travis 1998). Modified tubulin-containing arrays that look like the ones seen in c-metaphase cells treated with a high colchicine concentration have also been observed in Triticum aestivum after a $2 \mathrm{~h}$ exposure to high concentration (2-5 mM) (Karagiannidou 1995, Lazareva et al. 2003). The same outcome has also been observed after a long exposure to colchicine at low concentration $(<2 \mathrm{mM})$ in root meristems of Allium cepa (Utrilla et al. 1989) and Vigna sinensis (Apostolakos et al. 1990).

High levels of alpha-tubulin tyrosination have been shown to be associated with newly forming MT in plant cells (Duckett and Lloyd 1994, Gilmer et al. 1999). Likewise, the tubulin-containing arrays revealed in c-metaphase cells in our study presented a high level of tyrosination, with an epifluorescence intensity similar to that observed in the MT arrays of untreated cells. This pattern contrasts with the reduced amounts of tyrosinated alpha-tubulin observed in interphase and prophase cells from within the same treatment, revealing differential dynamics of these arrays in accordance with the cell cycle phase.

After $3 \mathrm{~h}$ of recovery, a persistence of the effects observed at the end of each treatment was detected. Tubulin depolymerization was achieved with low colchicine treatment, both in mitotic and in interphase cells, whereas after $3 \mathrm{~h}$ recovery following the high-concentration treatment, metaphase cells still exhibited cortical tubulin-containing structures with a tendency for a more parallel disposition, and interphase cells still presented the "tubulin cage" network structure. These results demonstrate the contrasting and opposite effects of colchicine in a concentration- 
dependent manner: absence of polymerized tubulin at low concentration, and the emergence of newly polymerized tubulin-containing structures at high concentration.

Nevertheless, $12 \mathrm{~h}$ after recovery from either treatment, typical microtubular cytoskeleton organization was observed in all cell cycle stages. This indicates that alterations in tubulin-containing arrays are maintained only for a short period of time after the treatment. Moreover, reestablishment of a cytoskeleton with normal MT $12 \mathrm{~h}$ after recovery is independent of colchicine concentration. It must be emphasized that there was an unusual presence of interphase cells with irregularly shaped nuclei and/or (additional) micronuclei in both treatments. The much higher frequency of these anomalous cells in the low-concentration treatment suggests that a prolonged absence of polymerized tubulin in c-metaphase cells inhibits the correct reorganization of chromatin in a nucleus, possibly resulting in loss of cell viability. These findings support the hypothesis of mitotic arrest in the low-concentration treatment, whereas c-metaphase cells are able to progress into the cell cycle in the high-concentration treatment (Fig. 4). Colchicine therefore induces a disruption of the usual synchrony between the DNA and MT cycles in terms of the classical configurations expected, since condensed chromosomes are observed either in the absence of any tubulin structure (after low-concentration treatment) or in the presence of new tubulin structures (after high-concentra-

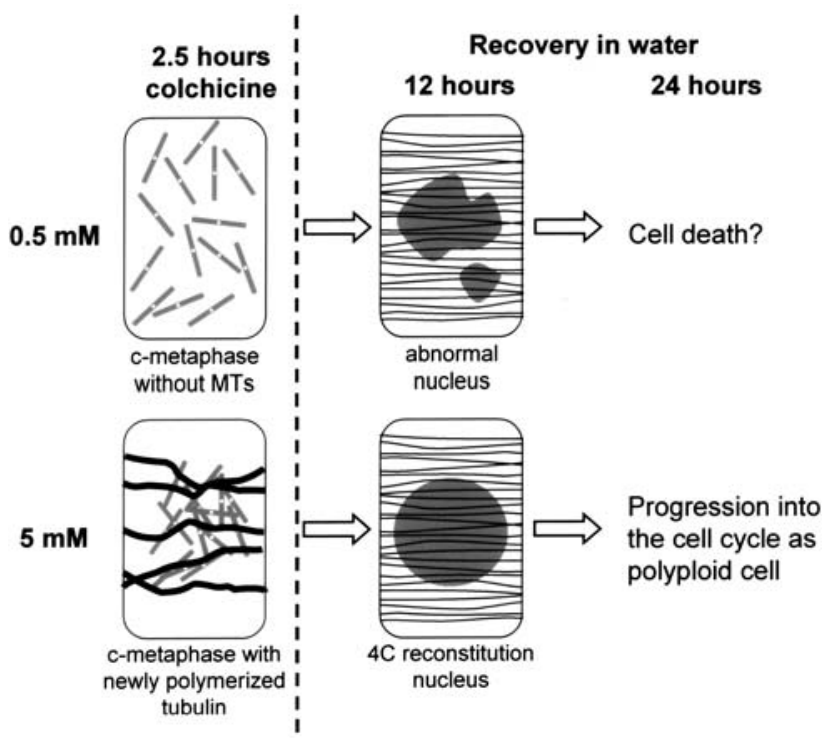

Fig. 4. Differential effects of colchicine concentration upon metaphase cell cytoskeleton and consequences for cell viability. Low concentration $(0.5 \mathrm{mM})$ induces MT depolymerization in metaphase resulting in cell abnormalities, while high concentration $(5 \mathrm{mM})$ promotes polymerization of new tubulin arrays allowing cell cycle progression tion treatment). In the latter case, the new tubulin-containing arrays are oriented towards the plasma membrane assuming an "interphase-like configuration".

Flow cytometric analysis $24 \mathrm{~h}$ after removal of cells from colchicine showed a direct correlation of the colchicine concentration with the presence of polyploid nuclei. In low-concentration-treated seedlings, only 2C and $4 \mathrm{C}$ nuclei were detected after $24 \mathrm{~h}$ of recovery, the same as observed in cells from untreated seedlings. In contrast, high colchicine concentration induced the appearance of $8 \mathrm{C}$ nuclei, corresponding to reconstituted $4 \mathrm{C}$ nuclei that had progressed into the cell cycle and completed the next $\mathrm{S}$ phase. The polyploid nature of the 8C nuclei was also confirmed by cytological evaluation of the frequency of cells with four NORs, since rye diploid cells are characterized by one pair of NOR loci, easily identifiable in interphase cells as two condensed perinucleolar knobs (Caperta et al. 2002). About 25\% of cells from seedlings exposed to high colchicine presented four individualized NOR loci after $24 \mathrm{~h}$ of recovery, contrasting with $2 \%$ of cells from untreated seedlings or those treated with the low concentration, confirming the data obtained by flow cytometry.

The present results contribute to an explanation, for the first time, of how the empirical use of low colchicine concentration treatments to produce c-metaphase cells for chromosome analysis (Caperta et al. 2002) contrasts with the high-concentration treatments normally used to induce polyploid plants (Hague and Jones 1987). Moreover, we can now also appreciate that colchicine-induced polyploidization is not only dependent on disassembly of the mitotic apparatus, since that condition per se is a common feature of both treatments. We now understand that the early appearance of newly polymerized tubulin-containing arrays is also a necessary condition. In contrast, the longer absence of tubulin-containing structures in the low-concentration treatment prevents c-mitotic cells from progressing into the cell cycle. This is consistent with previous descriptions of the occurrence of multiple micronuclei in cells treated with very low colchicine concentration over long periods (1 day) (Ghosh and Paweletz 1984, Labidi et al. 1987). Interestingly, rye root tip cells submitted to different colchicine treatments consistently show that chromosome grouping increases with long periods of exposure to low concentration (Morais-Cecílio et al. 1991).

The present work suggests that the emergence of new tubulin-containing arrays in c-metaphase cells is mediated by colchicine concentration, but earlier work by Lazareva et al. (2003) indicated that this might also be dependent on the duration of exposure. The interrelationship between 
variables (concentration and duration of treatment) may determine the critical moment of reassembly of chromatin into a common nuclear envelope. A delay in that event seems to induce anomalous nuclei unable to progress into the cell cycle. Instead, their early reconstitution in c-metaphase cells produces polyploid nuclei.

Although an understanding of tubulin dynamics under treatments with different concentrations at the biochemical level is beyond the scope of our study, we can speculate that the paradoxical effects of low and high colchicine concentrations on tubulin polymerization result from a requirement for a distinct concentration of tubulin-colchicine complexes for MT depolymerization and polymerization of new tubulin arrays. Another hypothesis is that high colchicine concentration promotes a direct transformation of MT into other tubulin-containing arrays, as has been observed in Allogromia laticollaris (Welnhofer and Travis 1998). Moreover, colchicine may also affect the cell-cyclerelated proteins, e.g., it has been shown that the level of cyclin B-like proteins increases in colchicine-arrested metaphase cells (Chaudhuri and Ghosh 1997). On the other hand, endoreduplication and polyploidy occur in cells expressing undegradable cyclin B (Weingartner et al. 2004). The potential action of colchicine on distinct cell components might be related to the paradoxical effect of drug concentration on the progression of the cell cycle.

\section{Acknowledgments}

We thank Augusta Barão for excellent technical assistance. R.N.J. thanks the Leverhulme Trust for financial support. Ana D. Caperta and Margarida Delgado contributed equally to this work.

\section{References}

Apostolakos P, Galatis B, Gatsaros C, Schnepf E (1990) Tubulin conformation in microtubule-free cells of Vigna sinensis: an immunofluorescent and electron microscopy study. Protoplasma 154: 132-143

Barow M, Meister A (2002) Lack of correlation between AT frequency and genome size in higher plants and the effect of nonrandomness of base sequences on dye binding. Cytometry 47: 1-7

Breitling F, Little M (1986) Carboxy-terminal regions on the surface of tubulin and microtubules. Epitope locations of YOL1/34, DM1A and DM1B. J Mol Biol 189: 367-370

Caperta AD, Neves N, Morais-Cecílio L, Malho R, Viegas W (2002) Genome restructuring in rye affects the expression, organization and disposition of homologous rDNA loci. J Cell Sci 115: 2839-2846

Chaudhuri SK, Ghosh S (1997) Monoclonal antibody raised against human mitotic cyclin B1, identifies cyclin B-like mitotic proteins in synchronized onion (Allium cepa) root meristem. Cell Biol Int 21: 159-166

Darlington CD, LaCour LF (1963) The handling of chromosomes. George Allen \& Unwin, London

Delgado M, Morais-Cecílio L, Neves N, Jones RN, Viegas W (1995) The influence of $\mathrm{B}$ chromosomes on rDNA organization in rye interphase nuclei. Chromosome Res 3: 487-491
Dewitte W, Murray JA (2003) The plant cell cycle. Annu Rev Plant Biol 54: 235-264

Duckett CM, Lloyd CW (1994) Giberellic acid-induced microtubule reorientation in dwarf pea is accompanied by rapid modification of an $\alpha$-tubulin isotype. Plant J 5: 363-372

Eigsti OJ, Dustin P (1955) Colchicine in agriculture, medicine, biology and chemistry. The Iowa State College Press, Ames, Iowa

Galbraith DW, Harkins KR, Maddox JM, Ayres NM, Sharma DP, Firoozabady E (1983) Rapid flow cytometric analysis of the cell cycle in intact plant tissues. Science 220: 1049-1051

Gerlach WL, Bedbrook JR (1979) Cloning and characterization of ribosomal RNA genes from wheat and barley. Nucleic Acids Res 8: 1869-1885

Ghosh S, Paweletz N (1984) Synchronous DNA synthesis and mitosis in multinucleate cells with one chromosome in each nucleus. Chromosoma (Berl) 89: 197-200

Gilmer S, Clay P, Macrae TH, Fowke LC (1999) Tyrosinated, but not detyrosinated, $\alpha$-tubulin is present in root tip cells. Protoplasma 210: 92-98

Givan AL (2001) Principles of flow cytometry: an overview. In: Darzynkiewicz Z, Robinson JP, Crissman H (eds) Cytometry, part A. Academic Press, London, pp 19-50 (Methods in cell biology, vol 63)

Hague LM, Jones RN (1987) Cytogenetics of Lolium perenne Part 4. Colchicine-induced variation in diploids. Theor Appl Genet 74: 233-241

Karagiannidou T, Eleftheriou EP, Tsekos I, Galatis B, Apostolakos P (1995) Colchicine-induced paracrystals in root cells of wheat (Triticum aestivum L.). Ann Bot 76: 23-30

Kilmartin JV, Wright B, Milstein C (1982) Rat monoclonal antitubulin antibodies derived by using a new nonsecreting rat cell line. J Cell Biol 93: 576-582

Labidi B, Frackowiak S, Hernandez-Verdun D (1987) Identification and sorting of micronuclei containing individual chromosomes. Exp Cell Res 173: 617-627

Lazareva EM, Polyakov VY, Chentsov YS, Smirnova EA (2003) Time and cell cycle dependent formation of heterogeneous tubulin arrays induced by colchicine in Triticum aestivum root meristem. Cell Biol Int 27: 633-646

Morais-Cecílio L, Queiroz A, Viegas W (1991) Differential effects of colchicine in genotypes with one or more haploid sets. Cytologia 56: 157-164

Morejohn LC, Fosket DE (1991) The biochemistry of compounds with anti-microtubule activity in plant cells. Pharmacol Ther 51: 217-230

Panda D, Goode BL, Feinstein SC, Wilson L (1995) Kinetic stabilization of microtubule dynamics at steady state by tau and microtubule-binding domains of tau. Biochemistry (Washington) 34: 11117-11127

Planchais S, Glab N, Inze D, Bergounioux C (2000) Chemical inhibitors: a tool for plant cell cycle studies. FEBS Lett 476: 78-83

Rieder CL, Palazzo RE (1992) Colcemid and the mitotic cycle. J Cell Sci 102: 387-392

Schwarzacher T, Heslop-Harrison JS (2000) Practical in situ hybridization. Bios, Oxford

Utrilla L, Sans J, de la Torre C (1989) Colchicine-resistant assembly of tubulin in plant mitosis. Protoplasma 152: 101-108

Weingartner M, Criqui M-C, Mészáros T, Binarova P, Schmit A-C, Helfer A, Derevier A, Erhardt M, Bögre L, Genschik P (2004) Expression of nondegradable cyclin B1 affects plant development and leads to endomitosis by inhibiting the formation of a phragmoplast. Plant Cell 16: 643-657

Welnhofer EA, Travis JL (1998) Evidence for a direct conversion between two tubulin polymers - microtubules and helical filaments - in the foraminiferan, Allogromia laticollaris. Cell Motil Cytoskeleton 41: $107-116$

Wick SM, Duniec J (1983) Immunofluorescence microscopy of tubulin and microtubule arrays in plant cells. I. Preprophase band development and concomitant appearance of nuclear envelope-associated tubulin. J Cell Biol 97: 235-243 